Research Paper

\title{
Impacts of CCL4 gene polymorphisms on hepatocellular carcinoma susceptibility and development
}

\author{
Bin Wang ${ }^{1}$, Ying-Erh Chou ${ }^{2,3}$, Ming-Yu Lien ${ }^{4,5}$, Chen-Ming Su 6 , Shun-Fa Yang ${ }^{3,7 凶}$, Chih-Hsin Tang $4,8 \bowtie$ \\ 1. Department of Hepatobiliary Surgery, Affiliated Dongyang Hospital of Wenzhou Medical University, Dongyang, Zhejiang, China. \\ 2. School of Medicine, Chung Shan Medical University, Taichung, Taiwan; \\ 3. Department of Medical Research, Chung Shan Medical University Hospital, Taichung, Taiwan; \\ 4. Graduate Institute of Basic Medical Science, China Medical University, Taichung, Taiwan; \\ 5. Division of Hematology and Oncology, Department of Internal Medicine, China Medical University Hospital, Taichung, Taiwan. \\ 6. Department of Biomedical Sciences Laboratory, Affiliated Dongyang Hospital of Wenzhou Medical University, Dongyang, Zhejiang, China. \\ 7. Institute of Medicine, Chung Shan Medical University, Taichung, Taiwan; \\ 8. Department of Biotechnology, College of Health Science, Asia University, Taichung, Taiwan.
}

$凶$ Corresponding authors: Chih-Hsin Tang, PhD, Graduate Institute of Basic Medical Science, China Medical University. E-mail: chtang@mail.cmu.edu.tw; or Shun-Fa Yang, PhD, Department of Medical Research, Chung Shan Medical University Hospital. E-mail: ysf@csmu.edu.tw

(c) Ivyspring International Publisher. This is an open access article distributed under the terms of the Creative Commons Attribution (CC BY-NC) license (https://creativecommons.org/licenses/by-nc/4.0/). See http://ivyspring.com/terms for full terms and conditions.

Received: 2017.02.12; Accepted: 2017.05.08; Published: 2017.07.19

\begin{abstract}
Hepatocellular carcinoma $(\mathrm{HCC})$ is the sixth most common cancer globally and the third most common cause of cancer mortality. In Taiwan, HCC is the second leading cause of cancer death. CCL4 (C-C chemokine ligand 4), is a macrophage inflammatory protein with a chief effect in inflammation and immune-regulation, and was documented in cancer progression by promoting instability in the tumor environment. Polymorphisms in chemokine genes help to determine host-pathogen interactions that influence chemokine levels. We investigated the effects of CCL4 gene polymorphisms on the risk of hepatocellular carcinoma (HCC) disease progression in a cohort of Taiwanese patients. We recruited total of 1,546 participants in current study, including 1,200 healthy control and 346 patients with HCC. Three single-nucleotide polymorphisms (SNPs) of the CCL4 gene were examined by a real-time PCR. We found that the A/G homozygotes of CCL4 rs 10491121 polymorphism reduced the risks for HCC. On the other hand, AG and GA haplotypes of 2 CCL4 SNPs (rs 1049112 and rs 171915) also reduced the risks for HCC by 0.025 and 0.515 fold, respectively. The present report is the first time to examine the risk factors associated with CCL4 SNPs in HCC progression in Taiwan.
\end{abstract}

Key words: CCL4; HCC; SNP; Susceptibility

\section{Introduction}

Hepatocellular carcinoma (HCC) is the sixth most common cancer globally and the third most common cause of cancer mortality [1, 2]. In Taiwan, HCC is the second leading cause of cancer death $[3,4]$. The development of HCC is a complex, multistep pathological process, mediated by liver fibrosis, cirrhosis, infection with hepatitis B virus (HBV) or hepatitis $\mathrm{C}$ virus $(\mathrm{HCV})$, alcohol consumption, and hereditary factors [4-6].

Polymorphisms in chemokine genes help to determine host-pathogen interactions that influence chemokine levels. A variety of polymorphisms have been identified in either the coding or non-coding regions of chemokine genes. Thus, genetic polymorphism plays an important role in determining susceptibility and resistance to HCC [7]. The CC chemokine macrophage inflammatory protein-1 $\beta$ (MIP-1 $\beta / C C L 4)$ is located on chromosome 17 (q11-q21) and is involved in immune responses produced by specific cells triggered by antigens or mitogenic signals and attract additional cells $[8,9]$. High CCL4 levels in the serum of cirrhotic patients indicate the presence of HCC [10]. We therefore investigated the effects of CCL4 gene polymorphisms on the risk of HCC disease progression in a cohort of Taiwanese patients. 
CCL4 gene single nucleotide polymorphisms (SNPs) influence gene expression, protein function and disease susceptibility in particular individuals $[11,12]$. SNP had potential predictive significance risk of HCC in previous studies [13, 14]. However, little is known about the association between CCL4 SNPs, HCC risk and disease progression. We therefore evaluated the diagnostic potential of three CCL4 SNPs as candidate biomarkers for susceptibility to HCC.

\section{Materials and Methods}

\section{Participants}

We enrolled 346 patients presenting with HCC to the Chung Shan Medical University Hospital, Taiwan, during the period 2007 through 2015. The 1200 anonymous healthy controls (HCs) were randomly selected from the Taiwan Biobank. All participants were Han Chinese. HCC patients were clinically staged at the time of diagnosis according to the 2002 American Joint Committee on Cancer (AJCC) TNM staging system, which incorporates tumor morphology, number of lymph nodes affected, and metastases [15]. Each study participant provided informed written consent and completed a structured questionnaire on sociodemographic characteristics, cigarette smoking and alcohol consumption. Liver cirrhosis was diagnosed with a liver biopsy, CT and magnetic MRI, or biochemical evidence of liver parenchymal damage with endoscopic esophageal or gastric varices. Written informed consent was obtained from all participants and the study was approved by the Institutional Review Board of Chung Shan Medical University Hospital prior to study commencement.

\section{Selection of CCL4 polymorphisms}

We selected the non-synonymous SNPs rs1634507 (in the promoter region; ID: C_7451708_10), rs10491121 (ID: C_11626804_10), and rs1719153 (3’UTR; ID: C_12120537_10) (Applied Biosystems) for this study. The rs1719153 CCL4 SNP has previously been found to modify HIV infection susceptibility and disease progression [16].

\section{Genomic DNA extraction}

Genomic DNA was extracted from whole blood specimens using QIAamp DNA blood mini kits (Qiagen, Valencia, CA, USA) according to the manufacturer's instructions. DNA was dissolved in TE buffer (10 mM Tris, $1 \mathrm{mM}$ EDTA; $\mathrm{pH} 7.8)$ and stored at $-20^{\circ} \mathrm{C}$.

\section{Real-time PCR}

The allelic discrimination of the CCL4 SNPs were assessed with the ABI StepOne ${ }^{\mathrm{TM}}$ Real-Time
PCR System (Applied Biosystems, Foster City, CA, USA) and analyzed with SDS v3.0 software (Applied Biosystems) using the TaqMan assay $[17,18]$.

\section{Statistical Analyses}

Chi-square analysis was used to confirm that the genotype distribution of each SNP was in Hardy-Weinberg equilibrium (HWE). A MannWhitney $U$-test and a Fisher's exact test were used to compare demographic characteristics distributions between HCs and HCC patients. The correlation between genotype frequencies, clinicopathologic characteristics and HCC cancer risk were examined by adjusted odds ratios (AORs) with $95 \%$ confidence intervals (CIs), after controlling for other covariates. The statistical analysis about haplotype was according to previously study [19]. A $p$ value of $<0.05$ was considered statistically significant. Data were analyzed using SAS statistical software (Version 9.1, 2005; SAS Institute Inc., Cary, NC, USA).

\section{Results}

No significant differences were found in terms of demographic characteristics between with the HCC patients and HCs (Table 1). Similarly, no significant differences existed between these two groups in regard to age $(p=0.114)$, gender $(p=0.261)$ or tobacco consumption $(p=0.493)$.

Whereas the serum levels of the common clinical pathological markers of HCC, a-Fetoprotein (AFP), aspartate transaminase (AST) and alanine transaminase (ALT) [20], were normal in HCs, levels were elevated in HCC patients. At baseline, $170 \mathrm{HCs}$ $(14.2 \%)$ and 129 HCC patients (37.3\%) self-reported alcohol consumption $(p<0.001)$. In the HCC cohort, 230 patients $(66.5 \%)$ had stage I/II HCC and 116 $(33.5 \%)$ had stage III/IV disease. To reduce the possible interference of confounding variables, AORs with 95\% CIs were estimated by multiple logistic regression models after controlling for alcohol consumption, $\mathrm{HBV}$ and $\mathrm{HCV}$ infection in each comparison.

Genotype distributions of SNPs rs1634507, rs10491121 and rs1719153 are presented in Table 2. In the HCs, all genotypic frequencies were in $\operatorname{HWE}(p>$ 0.05). In both HCs and HCC patients, the highest distribution frequencies for the rs1634507, rs10491121, and rs1719153 genes were, respectively, homozygous for $C / C$, heterozygous for $A / G$, and homozygous for A/A (Table 2). After adjusting for confounders, subjects with A/G homozygotes of the CCL4 rs10491121 polymorphism had a 0.665 -fold (95\% CI: $0.458-0.966 ; p<0.05)$ significantly lower risk of developing HCC compared to those with A/A homozygotes. There were no significant differences in 
the incidences of HCC patients with the rs 1634507 and rs1719153 polymorphisms compared to HCs.

No significant differences were found between the levels of AFP, AST, ALT or the AST/ALT ratio and the CCL4 polymorphisms in HCC patients (Table $3)$.

Table 1. The distributions of demographical characteristics and clinical parameters in 1200 controls and 346 patients with HCC.

\begin{tabular}{|c|c|c|c|}
\hline Variable & $\begin{array}{l}\text { Controls } \\
(\mathbf{N}=\mathbf{1 2 0 0}) \\
\end{array}$ & Patients $(\mathrm{N}=346)$ & $\mathrm{p}$ value \\
\hline \multicolumn{4}{|l|}{ Age (yrs) } \\
\hline$\leq 60$ & $557(46.4 \%)$ & $144(41.6 \%)$ & $\mathrm{p}=0.114$ \\
\hline$>60$ & $643(53.6 \%)$ & $202(58.4 \%)$ & \\
\hline \multicolumn{4}{|l|}{ Gender } \\
\hline Male & $840(70.0 \%)$ & $253(73.1 \%)$ & $p=0.261$ \\
\hline Female & $360(30.0 \%)$ & $93(26.9 \%)$ & \\
\hline \multicolumn{4}{|c|}{ Alcohol consumption } \\
\hline No & $1030(85.8 \%)$ & $217(62.7 \%)$ & $\mathrm{p}<0.001$ \\
\hline Yes & $170(14.2 \%)$ & $129(37.3 \%)$ & \\
\hline \multicolumn{4}{|c|}{ Tobacco consumption } \\
\hline No & $728(60.7 \%)$ & $203(58.7 \%)$ & $\mathrm{p}=0.493$ \\
\hline Yes & $471(39.3 \%)$ & $143(41.3 \%)$ & \\
\hline \multicolumn{4}{|l|}{ HBsAg } \\
\hline Negative & $1054(87.8 \%)$ & $202(58.4 \%)$ & $\mathrm{p}<0.001$ \\
\hline Positive & $146(12.2 \%)$ & $144(41.6 \%)$ & \\
\hline \multicolumn{4}{|l|}{ Anti-HCV } \\
\hline Negative & 1147 (95.6\%) & $185(53.5 \%)$ & \\
\hline Positive & $53(4.4 \%)$ & $161(46.5 \%)$ & \\
\hline AST (IU/L) & $26.2 \pm 13.3$ & $131.4 \pm 286.2$ & $\mathrm{p}<0.001$ \\
\hline ALT (IU/L) & $26.7 \pm 22.4$ & $111.3 \pm 224.3$ & $\mathrm{p}<0.001$ \\
\hline $\operatorname{AFP}(\mathrm{ng} / \mathrm{mL})$ & $3.86 \pm 14.62$ & $2967.9 \pm 14659.8$ & $p=0.0002$ \\
\hline \multicolumn{4}{|l|}{ Stage } \\
\hline I+II & & $230(66.5 \%)$ & \\
\hline III+IV & & $116(33.5 \%)$ & \\
\hline \multicolumn{4}{|c|}{ Tumor T status } \\
\hline$\leq \mathrm{T} 2$ & & $233(67.3 \%)$ & \\
\hline$>\mathrm{T} 2$ & & $113(32.7 \%)$ & \\
\hline \multicolumn{4}{|c|}{ Lymph node status } \\
\hline No & & $336(97.1 \%)$ & \\
\hline $\mathrm{N} 1+\mathrm{N} 2$ & & $10(2.9 \%)$ & \\
\hline \multicolumn{4}{|l|}{ Metastasis } \\
\hline M0 & & $328(94.8 \%)$ & \\
\hline \multicolumn{3}{|c|}{ vascular invasion } & \\
\hline No & & $283(87.8 \%)$ & \\
\hline Yes & & $63(18.2 \%)$ & \\
\hline
\end{tabular}

An analysis of distribution frequencies of CCL4 rs10491121 and rs1719153 haplotypes revealed that the most common haplotype in HCs was A/A $(40.2 \%)$, which was therefore selected as the reference. After controlling for alcohol consumption, HBV and HCV infection, the A/T CCL4 haplotype significantly reduced the risk of HCC disease progression by 0.025-fold (95\% CI: 0.007-0.093), while the G/A CCL4 haplotype significantly reduced the risk by 0.515 -fold (95\% CI: 0.387-0.686) (Table 4). The interaction effect between alcohol consumption and CCL4 haplotypes on HCC disease progression is shown in Table 5. The G/A haplotype was significantly more frequent among HCC patients than among HCs, both in non-drinkers $(21.9 \%$ vs $18.3 \%$, respectively; $\mathrm{p}=$ $0.0009)$ and drinkers $(23.3 \%$ vs $11.7 \% ; \mathrm{p}<0.001)$. Among the drinkers in the HCC cohort, those with the G/A haplotype had a 8.172-fold (95\% CI:4.862-13.734) greater risk of HCC disease progression compared to those with the A/A, A/T, or G/T haplotypes, in analyses that adjusted for $\mathrm{HBV}$ and $\mathrm{HCV}$ infection (Table 5).

Table 2. Distribution frequency of CCL4 genotypes in 1200 controls and 346 patients with HCC.

\begin{tabular}{lllll}
\hline Variable & $\begin{array}{l}\text { Controls } \\
(\mathbf{N = 1 2 0 0 )} \mathbf{n}(\%)\end{array}$ & $\begin{array}{l}\text { Patients } \\
(\mathbf{N = 3 4 6 )} \mathbf{n}(\mathbf{\%})\end{array}$ & OR (95\% CI) & AOR (95\% CI) \\
\hline rs1634507 & & & & \\
CC & $575(47.9 \%)$ & $167(48.3 \%)$ & 1.00 & 1.00 \\
AC & $517(43.1 \%)$ & $148(42.8 \%)$ & 0.986 & 0.971 \\
& & & $(0.767-1.267)$ & $(0.699-1.347)$ \\
AA & $108(9.0 \%)$ & \multirow{2}{*}{$31(8.9 \%)$} & 0.988 & 1.078 \\
& & & $(0.640-1.527)$ & $(0.618-1.881)$ \\
AC+AA & $625(52.1 \%)$ & $179(51.7 \%)$ & 0.986 & 0.989 \\
& & & $(0.776-1.253)$ & $(0.725-1.350)$
\end{tabular}

rs10491121

AA $\quad 295(24.6 \%)-103(29.8 \%)-1.00-1.00$

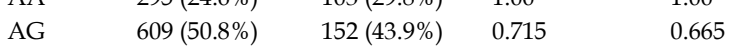

\begin{tabular}{ll}
$(0.537-0.952)^{*} \quad(0.458-0.966)^{*}$ \\
\hline
\end{tabular}

GG $296(24.6 \%) \quad 91(26.3 \%) \quad 0.880 \quad 0.822$

$\begin{array}{lllll}\text { AG+GG } & 905(75.4 \%) & 243(70.2 \%) & (0.636-1.218) & (0.536-1.260) \\ & & & \end{array}$

$(0.590-1.003) \quad(0.506-1.013)$

rs1719153

\begin{tabular}{lllll} 
AA & $556(46.3 \%)$ & $174(50.3 \%)$ & 1.00 & 1.00 \\
AT & $532(44.3 \%)$ & $141(40.8 \%)$ & 0.847 & 0.857 \\
& & & $(0.658-1.090)$ & $(0.617-1.190)$ \\
TT & $112(9.4 \%)$ & \multirow{2}{*}{$31(8.9 \%)$} & 0.884 & 0.776 \\
& & & $(0.574-1.363)$ & $(0.452-1.332)$ \\
AT+TT & $644(53.7 \%)$ & $172(49.7 \%)$ & 0.853 & 0.840 \\
& & & $(0.672-1.084)$ & $(0.616-1.146)$ \\
\hline
\end{tabular}

The odds ratios (ORs) and with their $95 \%$ confidence intervals (CIs) were estimated by logistic regression models. The adjusted odds ratios (AORs) with their $95 \%$ confidence intervals (CIs) were estimated by multiple logistic regression models after controlling for alcohol consumption, $\mathrm{HBsAg}$, and HCV. ${ }^{*} \mathrm{p}$ value $<0.05$ as statistically significant

Table 3. Association of CCL4 genotypic frequencies with HCC laboratory status.

\begin{tabular}{lllll}
\hline Characteristic & $\begin{array}{l}\text { a-Fetoprotein a } \\
\text { (ng/mL) }\end{array}$ & $\begin{array}{l}\text { AST a } \\
\text { (IU/L) }\end{array}$ & $\begin{array}{l}\text { ALT a } \\
\text { (IU/L) }\end{array}$ & $\begin{array}{l}\text { AST/ALT } \\
\text { ratio a }^{\text {a }}\end{array}$ \\
\hline rs1634507 & & & & \\
CC & $2857.4 \pm 1166.4$ & $162.3 \pm 30.0$ & $136.0 \pm 23.0$ & $1.51 \pm 0.14$ \\
AC+AA & $3071.0 \pm 1069.2$ & $102.7 \pm 9.8$ & $88.2 \pm 9.0$ & $1.45 \pm 0.08$ \\
p value & 0.893 & 0.060 & 0.054 & 0.727 \\
& & & & \\
rs10491121 & & & & \\
AA & $3112.5 \pm 1681.9$ & $149.0 \pm 30.0$ & $128.8 \pm 27.3$ & $1.53 \pm 0.19$ \\
AG+GG & $2906.6 \pm 869.1$ & $124.0 \pm 17.9$ & $103.9 \pm 12.7$ & $1.46 \pm 0.08$ \\
p value & 0.914 & 0.459 & 0.408 & 0.726
\end{tabular}

rs1719153

$\begin{array}{lllll}\text { AA } & 2755.6 \pm 1120.0 & 159.5 \pm 28.8 & 132.8 \pm 22.0 & 1.51 \pm 0.13\end{array}$

$\begin{array}{lllll}\text { AT+TT } & 3182.7 \pm 1111.9 & 103.0 \pm 10.2 & 89.5 \pm 9.4 & 1.46 \pm 0.08\end{array}$ $\begin{array}{lllll}\mathrm{p} \text { value } & 0.787 & 0.065 & 0.072 & 0.748\end{array}$

Mann-Whitney U test was used between two groups. a Mean \pm S.E. 
Table 4. Frequencies of CCL4 haplotypes in HCC patients and control subjects.

\begin{tabular}{|c|c|c|c|c|c|}
\hline \multicolumn{2}{|c|}{ Haplotype block } & \multirow{2}{*}{$\begin{array}{l}\text { Controls } \\
\mathrm{n}=2400\end{array}$} & \multicolumn{3}{|l|}{ Patients } \\
\hline $\begin{array}{l}\text { rs10491121 } \\
\text { A/G }\end{array}$ & $\begin{array}{l}\text { rs1719153 } \\
\mathrm{A} / \mathrm{T}\end{array}$ & & $\mathrm{n}=692$ & OR $(95 \% \mathrm{CI})$ & $\begin{array}{l}\text { AOR (95\% } \\
\text { CI) }\end{array}$ \\
\hline \multicolumn{6}{|c|}{ Global haplotype test $(P<0.001)$} \\
\hline A & A & $\begin{array}{l}964 \\
(40.2 \%)\end{array}$ & $\begin{array}{l}355 \\
(51.3 \%)\end{array}$ & 1.00 & 1.00 \\
\hline A & $\mathrm{T}$ & $\begin{array}{l}235 \\
(9.8 \%)\end{array}$ & $3(0.4 \%)$ & $\begin{array}{l}0.035 \\
(0.011-0.109)^{\mathrm{b}}\end{array}$ & $\begin{array}{l}0.025 \\
(0.007-0.093) \text { c }\end{array}$ \\
\hline G & A & $\begin{array}{l}680 \\
(28.3 \%)\end{array}$ & $\begin{array}{l}134 \\
(19.4 \%)\end{array}$ & $\begin{array}{l}0.535 \\
(0.429-0.668)^{\mathrm{d}}\end{array}$ & $\begin{array}{l}0.515 \\
(0.387-0.686) \mathrm{e}\end{array}$ \\
\hline G & $\mathrm{T}$ & $521(21.7)$ & $\begin{array}{l}200 \\
(28.9 \%)\end{array}$ & $\begin{array}{l}1.042 \\
(0.851-1.278)\end{array}$ & $\begin{array}{l}0.988 \\
(0.756-1.290)\end{array}$ \\
\hline $\begin{array}{l}\text { a Adjusting for } \\
\text { b } P<0.001 \\
\text { c } P<0.001 \\
\text { d } P<0.001 \\
\text { e } P<0.001\end{array}$ & the effects of & alcohol consu & umption, $\mathrm{H}$ & $\mathrm{HBAAg}$, and $\mathrm{HCV}$ & \\
\hline
\end{tabular}

Table 5. Combined effect of alcohol consumption and CCL4 haplotypes on HCC development.

\begin{tabular}{|c|c|c|c|c|}
\hline \multirow{2}{*}{$\begin{array}{l}\text { Alcohol } \\
\text { consumption }\end{array}$} & \multirow{2}{*}{$\begin{array}{l}\text { CCL4 } \\
\text { haplotype }\end{array}$} & Controls & Patients & \multirow[t]{2}{*}{$\operatorname{AOR}(95 \% \mathrm{CI})^{\mathrm{b}}$} \\
\hline & & $\mathrm{n}=2400$ & $n=692$ & \\
\hline Yes & G-A & $43(2.5 \%)$ & $73(13.0 \%)$ & $\begin{array}{l}8.172 \\
(4.862-13.734)^{c}\end{array}$ \\
\hline Yes & Othersa & $\begin{array}{l}198 \\
(11.7 \%)\end{array}$ & $\begin{array}{l}131 \\
(23.3 \%)\end{array}$ & $\begin{array}{l}2.725 \\
(1.942-3.822) c\end{array}$ \\
\hline No & G-A & $\begin{array}{l}310 \\
(18.3 \%)\end{array}$ & $\begin{array}{l}123 \\
(21.9 \%)\end{array}$ & $\begin{array}{l}1.720 \\
(1.248-2.370)^{\mathrm{d}}\end{array}$ \\
\hline No & Othersa & $\begin{array}{l}1145 \\
(67.5 \%)\end{array}$ & $\begin{array}{l}235 \\
(41.8 \%)\end{array}$ & 1.000 (reference) \\
\hline
\end{tabular}

a Other haplotypes included A-A, A-T, and G-T

b Adjusting for the effects of $\mathrm{HBsAg}$, and HCV

c $P<0.001$

d $P=0.0009$

\section{Discussion}

The chemokine CCL4 plays a key role in many cancer cell types [21-23]. For instance, CCL4 increases invasion and migration of prostate cancer cells through regulation of the integrin pathway [24]. Recent evidence also suggests that CCL4 promotes tumor growth and angiogenesis [25]. In contrast, a high level of CCL4 expression correlates with a more favorable prognosis in esophageal squamous cell carcinoma, which suggests that CCL4 may recruit tumor infiltrating CD8+ $\mathrm{T}$ lymphocytes and thus affect the cancer microenvironment [26]. Previous studies have indicated that the A/T haplotype and $\mathrm{T}$ alleles of rs1719153 occurring in CCL4 SNPs are more frequently expressed in HCs than in patients with HIV-1 infection [16, 27]. To the best of our knowledge, this current study is the first to investigate the distribution of the rs1634507, rs10491121 and rs1719153 SNPs and their possible association with susceptibility to HCC. We also examined the associates of these CCL4 SNPs combined with environmental carcinogens, leading to a susceptibility to HCC. In analyses adjusting for confounding factors, the rs10491121 A/G homozygous polymorphism was associated with a significantly lower risk of developing HCC compared to with the rs10491121 A/A homozygous polymorphism (95\% CI: 0.458-0.966; $p<0.05$ ).

It has been reported that the CCL4 rs1634507 polymorphism in promoter regions is not associated with HIV infection, although it is associated with more rapid progression of acquired immune deficiency syndrome [27]. The CCR5 is specific receptor of CCL4 [28]. Therefore, the gene variants could enhance CCL4 expression, increasing the interaction with more CCR5 receptors, promoting their internalization, and hence supporting entry restriction of HIV-1 R5 strains [27]. On the other hand, the CCL4 production from monocytic myeloidderived suppressor cells and tumor-infiltrating granulocyte recruit high numbers of regulatory $\mathrm{T}$ cells (Tregs) through CCR5 receptor in melanoma and lymphoma [29]. CCL4 induced tumor growth through regulation of antitumor immune responses by a network of MDSCs and Tregs within the tumor microenvironment. Tumor microenvironments impact on disease progression, response to therapy and prognosis [30]. Gene polymorphisms may enhance CCL4 expression and inhibit antitumor immunity in the tumor microenvironment. Although the functional importance of the CCL4 SNP is not examined in this study, a relationship with the risk of HCC is initiated based on the locations of the examined variants.

The linkage disequilibrium (LD) express across the human genome. Therefore, the LD could be used as genetic markers to locate adjacent variants that participate to detection and treatment of disease. Otherwise, the haplotype analyses can provide the contribution to the susceptibility of disease [31]. We evaluated impacts of different haplotype combinations of 2 CCL4 SNPs (rs1049112 and rs171915) to the risk of HCC and eventually found that the AT and GA haplotype showed a low risk for HCC. It is possible that the AT and GA haplotypes of CCL4 are in LD with other functional polymorphisms that are responsible for the susceptibility to HCC. It has been reported that CCL4 secretion by CD4+antigen-presenting cell APC complexes, which correlated with increased cross-priming of CCR5-expressing CD8+ T lymphocytes [32]. Then CD8+ $\mathrm{T}$ lymphocytes exit the draining lymph node and migrate to the tumor site, where they exert their cytotoxic function on cancer cells. High levels of CCL4 in the ESCC patients predicted prolonged survival. CDR5+CD8+ T lymphocytes were recruited by CCL4 into ESCC lesions [26]. Whether CCL4 polymorphism recruit different $\mathrm{T}$ lymphocyte subsets increasing 
anti-tumor immunity, which benefits the inhibition of tumor growth are needs further examination.

The current study provides novel insights into CCL4 SNPs in regard to HCC susceptibility and disease progression. However, we dose not recruited the survival results of HCC patients. Future research could evaluate the association of CCL4 polymorphisms with survival of HCC patients. Furthermore, it would be advisable to collect data on a larger number of patients for analysis of the functions of CCL4 polymorphisms in HCC. In summary, this study provides evidence supporting an association between CCL4 polymorphisms and HCC risk. CCL4 polymorphisms may therefore serve as a useful prognosis marker for HCC treatment.

\section{Acknowledgments}

This work was supported by grants from the Ministry of Science and Technology of Taiwan (MOST 103-2628-B-039-002-MY3) and China Medical University Hospital (CMU106-015).

\section{Competing Interests}

The authors declare no conflicts of interest.

\section{References}

1. Siegel R, Naishadham D, Jemal A. Cancer statistics, 2012. CA: a cancer journal for clinicians. 2012; 62: 10-29.

2. Padma VV. An overview of targeted cancer therapy. BioMedicine. 2015; 5: 19.

3. Bosch FX, Ribes J, Cleries R, Diaz M. Epidemiology of hepatocellular carcinoma. Clin Liver Dis. 2005; 9: 191-211, v.

4. Wu CY, Huang HM, Cho DY. An acute bleeding metastatic spinal tumor from HCC causes an acute onset of cauda equina syndrome. BioMedicine. 2015; 5: 18.

5. Farazi PA, DePinho RA. Hepatocellular carcinoma pathogenesis: from genes to environment. Nat Rev Cancer. 2006; 6: 674-87.

6. Forner A, Llovet JM, Bruix J. Hepatocellular carcinoma. Lancet. 2012; 379: 1245-55.

7. Xu Y, Li L, Xiang X, Wang H, Cai W, Xie J, et al. Three common functional polymorphisms in microRNA encoding genes in the susceptibility to hepatocellular carcinoma: a systematic review and meta-analysis. Gene. 2013; 527: 584-93.

8. Menten P, Wuyts A, Van Damme J. Macrophage inflammatory protein-1. Cytokine \& growth factor reviews. 2002; 13: 455-81.

9. Maurer M, von Stebut E. Macrophage inflammatory protein-1. The international journal of biochemistry \& cell biology. 2004; 36: 1882-6

10. Sadeghi M, Lahdou I, Oweira H, Daniel V, Terness P, Schmidt J, et al. Serum levels of chemokines CCL4 and CCL5 in cirrhotic patients indicate the presence of hepatocellular carcinoma. British journal of cancer. 2015; 113: $756-62$

11. Shastry BS. SNP alleles in human disease and evolution. J Hum Genet. 2002; 47: 561-6.

12. Chang WS, Liu LC, Hsiao CL, Su CH, Wang HC, Ji HX, et al. The contributions of the tissue inhibitor of metalloproteinase- 1 genotypes to triple negative breast cancer risk. BioMedicine. 2016; 6: 4 .

13. Wang B, Yeh CB, Lein MY, Su CM, Yang SF, Liu YF, et al. Effects of HMGB1 Polymorphisms on the Susceptibility and Progression of Hepatocellular Carcinoma. International journal of medical sciences. 2016; 13: 304-9.

14. Yang SF, Yeh CB, Chou YE, Lee HL, Liu YF. Serpin peptidase inhibitor (SERPINB5) haplotypes are associated with susceptibility to hepatocellular carcinoma. Scientific reports. 2016; 6: 26605.

15. Vauthey JN, Lauwers GY, Esnaola NF, Do KA, Belghiti J, Mirza N, et al. Simplified staging for hepatocellular carcinoma. J Clin Oncol. 2002; 20: 1527-36.

16. Celerino da Silva R, Victor Campos Coelho A, Claudio Arraes L, Andre Cavalcanti Brandao L, Lima Guimaraes R, Crovella S. Chemokines SNPs in HIV-1+ Patients and Healthy Controls from Northeast Brazil: Association with Protection against HIV-1 Infection. Current HIV research. 2016; 14: 340-5.
17. Lin YJ, Ho TJ, Lin TH, Hsu WY, Huang SM, Liao CC, et al. P-coumaric acid regulates exon 12 splicing of the ATP7B gene by modulating hnRNP A1 protein expressions. Biomedicine (Taipei). 2015; 5: 10

18. Li TC, Li CI, Liao LN, Liu CS, Yang CW, Lin CH, et al. Associations of EDNRA and EDN1 polymorphisms with carotid intima media thickness through interactions with gender, regular exercise, and obesity in subjects in Taiwan: Taichung Community Health Study (TCHS). Biomedicine (Taipei). 2015; 5: 8.

19. Barrett JC, Fry B, Maller J, Daly MJ. Haploview: analysis and visualization of LD and haplotype maps. Bioinformatics. 2005; 21: 263-5.

20. Simpson HN, McGuire BM. Screening and detection of hepatocellular carcinoma. Clin Liver Dis. 2015; 19: 295-307.

21. Sasaki S, Baba T, Nishimura T, Hayakawa Y, Hashimoto S, Gotoh N, et al. Essential roles of the interaction between cancer cell-derived chemokine, CCL4, and intra-bone CCR5-expressing fibroblasts in breast cancer bone metastasis. Cancer letters. 2016; 378: 23-32.

22. Nguyen-Hoai T, Pham-Duc M, Gries M, Dorken B, Pezzutto A, Westermann J. CCL4 as an adjuvant for DNA vaccination in a Her2/neu mouse tumor model. Cancer gene therapy. 2016; 23: 162-7.

23. Takahashi K, Sivina M, Hoellenriegel J, Oki Y, Hagemeister FB, Fayad L, et al. CCL3 and CCL4 are biomarkers for B cell receptor pathway activation and prognostic serum markers in diffuse large B cell lymphoma. British journal of haematology. 2015; 171: 726-35.

24. Fang LY, Izumi K, Lai KP, Liang L, Li L, Miyamoto H, et al. Infiltrating macrophages promote prostate tumorigenesis via modulating androgen receptor-mediated CCL4-STAT3 signaling. Cancer research. 2013; 73: 5633-46.

25. Krizia Rohena-Rivera MMS-V, Diana A Aponte-Colón, Ingrid S Forestier-Román, Mario E Quintero-Aguiló, Magaly Martínez-Ferrer. CCL-4 enhances prostate cancer migration and invasion by modulating integrin expression. Int J Clin Exp Med. 2016;9(3):5426-5438

26. Liu JY, Li F, Wang LP, Chen XF, Wang D, Cao L, et al. CTL- vs Treg lymphocyte-attracting chemokines, CCL4 and CCL20, are strong reciprocal predictive markers for survival of patients with oesophageal squamous cell carcinoma. British journal of cancer. 2015; 113: 747-55.

27. Modi WS, Lautenberger J, An P, Scott K, Goedert JJ, Kirk GD, et al. Genetic variation in the CCL18-CCL3-CCL4 chemokine gene cluster influences HIV Type 1 transmission and AIDS disease progression. American journal of human genetics. 2006; 79: 120-8

28. Wang Y, Liu T, Yang N, Xu S, Li X, Wang D. Hypoxia and macrophages promote glioblastoma invasion by the CCL4-CCR5 axis. Oncology reports. 2016; 36: 3522-8

29. Schlecker E, Stojanovic A, Eisen C, Quack C, Falk CS, Umansky V, et al. Tumor-infiltrating monocytic myeloid-derived suppressor cells mediate CCR5-dependent recruitment of regulatory $\mathrm{T}$ cells favoring tumor growth. Journal of immunology. 2012; 189: 5602-11.

30. Junttila MR, de Sauvage FJ. Influence of tumour micro-environment heterogeneity on therapeutic response. Nature. 2013; 501: 346-54.

31. Shifman S, Bronstein M, Sternfeld M, Pisante-Shalom A, Lev-Lehman E, Weizman A, et al. A highly significant association between a COMT haplotype and schizophrenia. American journal of human genetics. 2002; 71: 1296-302.

32. Askew D, Su CA, Barkauskas DS, Dorand RD, Myers J, Liou R, et al. Transient Surface CCR5 Expression by Naive CD8+ T Cells within Inflamed Lymph Nodes Is Dependent on High Endothelial Venule Interaction and Augments Th Cell-Dependent Memory Response. Journal of immunology. 2016; 196: 3653-64 